\title{
Willingness to Stay of Tourism Lifestyle Entrepreneurs: A Configurational Perspective
}

\author{
Álvaro Dias ${ }^{1,2, *(1)}$ and Graça M. Silva ${ }^{3}$ (1) \\ 1 ECEO/TRIE, Universidade Lusófona, 1749-024 Lisbon, Portugal \\ 2 DMOGG, ISCTE-IUL, 1649-026 Lisbon, Portugal \\ 3 ADVANCE/CSG, ISEG, Lisbon School of Economics \& Management, Universidade de Lisboa, \\ 1249-078 Lisbon, Portugal; gracamsilva@iseg.ulisboa.pt \\ * Correspondence: alvaro.dias1@gmail.com
}

Citation: Dias, Á.; Silva, G.M. Willingness to Stay of Tourism

Lifestyle Entrepreneurs: A

Configurational Perspective. Sustainability 2021, 13, 13519 .

https://doi.org/10.3390/su132413519

Academic Editors: João Carlos

Correia Leitão and Dina

Batista Pereira

Received: 10 November 2021

Accepted: 3 December 2021

Published: 7 December 2021

Publisher's Note: MDPI stays neutral with regard to jurisdictional claims in published maps and institutional affiliations.

Copyright: (c) 2021 by the authors. Licensee MDPI, Basel, Switzerland. This article is an open access article distributed under the terms and conditions of the Creative Commons Attribution (CC BY) license (https:// creativecommons.org/licenses/by/ $4.0 /)$.

\begin{abstract}
Tourism lifestyle entrepreneurs play an essential role in the innovation, sustainability, and competitiveness of tourism destinations. Thus, the ability of a destination to attract and retain this type of entrepreneur is an essential factor in strategic decisions. The limited research on this class of entrepreneurs implies that decision makers have little information about the factors that contribute to their willingness to stay in a particular destination. To address this challenge, this study employs a mixed-method approach, combining a quantitative survey-based study with a qualitative study by means of in-depth interviews. Based on survey data and using fuzzy set qualitative comparative analysis, this study identifies three equifinal configurations of antecedent factors (entrepreneurial self-efficacy, community-centered strategy, community attachment, and place attachment) that lead to a willingness to stay. Place attachment is the single-core condition. Moreover, the findings show that TLEs are not a homogeneous group. On the contrary, these entrepreneurs are driven by different motives and personal backgrounds. These results represent important insights for the definition of more sustainable strategies in destinations.
\end{abstract}

Keywords: community attachment; qualitative comparative analysis; willingness to stay; place attachment; self-efficacy

\section{Introduction}

Differentiation is an essential imperative for the competitiveness of tourism destinations. To this end, innovation through genuine and differentiating experiences is essential [1]. Small businesses and, in particular, tourism lifestyle entrepreneurs (TLEs), to which are associated not only a significant part of the innovation generated in destinations [2] but also more sustainable practices [3], are essential to the development of tourism destinations. TLEs can be defined as business owners that are primarily motivated by lifestyle and quality of life reasons. As such, their businesses are operated by incorporating non-financial factors [4]. They can be either locals or migrants who move to a location to start a tourism business [5].

TLEs are focused on preserving both the local lifestyle and the environment and traditions of the local community [6,7]. These characteristics align with the growing trends in the industry and those that are being enhanced by pandemic [8], generating the need to seek new market segments that value factors such as genuineness, sustainability, and innovation. TLEs are recognized for identifying and adapting to niche markets [9] and for promoting an innovation spillover effect in and between destinations [10]. In turn, the link to the local area is another characteristic of the TLEs and is associated with competitiveness and innovation, since it allows them to access local knowledge that is unique and difficult to imitate [11].

Previous research recognizes that TLEs have advantages over other companies in product and service innovation [12]. Being essential for local development, the attention 
should be focused on the location decisions [13]. Thus, the question arises of how to attract and retain them in each tourist destination. Entrepreneurship research points to several factors, such as local infrastructure, local economic conditions, institutional framework, individual motivations, and location-based motivations [13]. However, the context of tourism entrepreneurship research takes on different contours, especially in the case of TLEs, where location decisions are linked to non-economic factors such as place and community attachment. On the other hand, small businesses run by TLEs show unique characteristics compared with other companies, since they pursue objectives other than economic ones [4]. In this sense, this article aims (1) to identify the factors that contribute to attracting and retaining this specific group of entrepreneurs and (2) explore the different combination of factors leading to TLEs' willingness to stay.

Previous research links location choice factors to the pursuit of a particular lifestyle [4]. However, it is unclear whether these factors are determinants of willingness to stay in a destination. For example, what happens if the business is not performing as expected, (i.e., if the actual results do not match what was anticipated)? Will they end the business and look for another location? These questions are related to the concept of self-efficacy, an entrepreneurial subjective measure where, for example, a revenue of EUR 100,000 is totally satisfying for one entrepreneur and clearly insufficient to another. Despite pursuits other than financial goals, these entrepreneurs still need to sustain themselves. Moreover, previous research also acknowledges the role that self-efficacy plays in retaining TLEs in a destination [14]. However, not all these entrepreneurs pursue business success [15], which suggests that there are different combinations that should be further explored to understand in which situations TLEs value business success as a reason to stay.

This study applies a sequential mixed method approach, starting with a quantitative study based on survey data, followed by a qualitative study using in-depth interviews. Survey data were analyzed using a configurational approach, that being fuzzy set qualitative comparative analysis (fsQCA). This study contributes to the existing knowledge on tourism entrepreneurship ecosystems by identifying different configurations of antecedent factors that contribute to the willingness to stay (WTS), where place attachment represents a necessary but insufficient condition, bringing important insights about the TLEs' attraction and retention factors. This underexplored topic is essential for developing tourism destination innovation and competitiveness. Moreover, from a methodological perspective, this research use fsQCA, which is recognized as an innovative and useful methodology for tourism research [16]. To the best of our knowledge, this is the first study that uses this methodology in the context of tourism lifestyle entrepreneurship.

\section{Conceptual Foundations}

Studies addressing TLEs should consider the unique characteristics of these entrepreneurs. Dias et al. [11] and Bosworth and Farrel [6] suggested that traditional models that apply to other entrepreneurs should be revisited considering these characteristics. They seek a better quality of life, and to this end, they are willing to change from their previous life to create a business where they can reach the desired lifestyle [17], which drives some of their distinctive characteristics. In the context of tourism, the main differences relate to the way they run their businesses and the role of the place and community in location decisions. Both aspects will be further explored in Sections 2.1 and 2.2, respectively. Section 2.3 discusses the strategies followed by TLEs to promote better integration into the community as well as acquire and transform local knowledge into new experiences and products, in addition to it impacts on the willingness to stay.

\subsection{Business Goals and Entrepreneurial Self-Efficacy}

Frequently, the businesses run by TLEs require few skills and experience [5]. Due to the low entry barriers in most tourism businesses, these entrepreneurs usually evidence some unsophisticated managerial approaches [4], revealing weaknesses such as few resources [18] and low knowledge of the business or a lack of management experience [19]. 
The business is also dominated by the entrepreneurial family, acting as a valuable source of human capital but also with a probable negative impact on the efficiency and quality of the operation [7].

Probably one of the most distinctive characteristics of TLEs is the definition of business goals. It is noted that these entrepreneurs use a combination of financial and non-financial goals [4]. However, the importance of each remains unclear. For example, previous research reported that they are motivated purely by lifestyle goals, with financial goals being merely instrumental [6]. Furthermore, Morrison [13] recognized that a significant part of them is not growth-oriented. However, there are other situations that are more business-oriented and focused on financial outcomes which are also acknowledged [20]. Wang et al. [15] identified four shifts in TLE motivations: from lifestyle to business-oriented, maintenance of lifestyle, from business-oriented to lifestyle, and maintenance of business orientation.

Given that there is a plurality of motivations for business, measuring the success of these businesses only from an economic financial point of view is reductive [21], not the least because using a dichotomy between financial and lifestyle objectives is an artificial simplification [9]. Thus, the ventures managed by TLEs are evaluated by a set of variables of a diverse nature. Aside from quality of life, community improvement and environmental, social [12], cultural [9], and ideological [21] goals are also relevant objectives of TLEs. This multiplicity of objectives suggests that the most appropriate way to assess the performance of TLEs involves subjective performance measures [22], also referred to as entrepreneurial self-efficacy, defined as the entrepreneur's beliefs in his or her capabilities to successfully achieve their entrepreneurial goals [23]. Due to the difficulty to access financial data from small tourism businesses, Fu et al. [20] considered entrepreneurial self-efficacy a good indicator to measure business performance.

Previous research acknowledges the role that entrepreneurial self-efficacy plays in the retention of TLEs [14]. However, it is unclear in which situations this occurs, as many of these businesses are run using non-financial indicators. Although lifestyle pursuit and entrepreneurial success are not mutually exclusive $[9,24]$, research suggests that preferences are not uniform, and therefore, different degrees of relevance regarding business performance should be considered in relation to the willingness to stay.

\subsection{Place and Community Attachment}

The link to the place plays an important role in the context of TLEs [9]. The integration in the place and its community also represents another distinctive feature and is of particular importance in the competitiveness of these small businesses, since it is the source of the knowledge on which the idiosyncrasy of the experiences they offer is based [24,25]. Research on tourism entrepreneurship cannot be dissociated from the social context [4]. The place and community attachment are most effectively realized by these entrepreneurs, as the boundary between personal life and business is virtually non-existent [5], benefiting from a higher level of cooperation within the community [26] and providing not only a unique social exchange system [27] but an important component of the TLE perspective of quality of life [17].

As a result of the strong link to the community and place, the products or experiences offered by these entrepreneurs are more associated with the place's traditions and identity when compared with those of large companies [28]. However, although identity construction is the basis of the narrative of TLEs, it is dependent on the degree of integration in the community [9]. Opportunities do not arise from business activities but from social connections [2]. Thus, the difficulties and weaknesses pointed out above are usually overcome through collaborative processes [4], which promote the development of shared values and increase the ability to learn from other entrepreneurs [24].

Considering the role that the community and place play in business development and innovation, it is natural that they are also associated with the willingness to stay [14] because, on the one hand, conducting experiences in a specific place implies that they 
are mainly developed with endogenous human capital [1], and on the other hand, the geographical location and social conditions are key factors in the location decision [22].

\subsection{Community-Centered Strategy: A Key Element for Willingness to Stay}

Place attachment is considered an informal and passive channel for the acquisition and transformation of local knowledge into new tourism products and experiences [11,29]. Considering that tourism experiences are strongly linked to the spirit of the place and its people [25], and that local knowledge is tacit and context sensitive [19], it is necessary that TLEs adopt more active and deliberate measures that promote, on the one hand, an active acquisition of this knowledge and, on the other hand, promote a better integration of their business within the local community [24]. In this sense, community-centered strategies favor the identification of market opportunities [2] and facilitate the process of acquiring local knowledge [11,24].

Community-centered strategies allow the entrepreneur to overcome the weaknesses previously identified for several reasons. First, they promote trust and cooperation [26] instead of competition. Second, they also enhance the active engagement of local stakeholders in the formation of tourism experiences [2]. Third, these strategies also address the demand side by involving tourists in events and other local activities, which provides new narratives [24] and experiences with more added value [30]. Finally, by promoting community participation in tourism activities, they contribute to enhancing the local identity [9] and creating more integrative and sustainable behavior [31]. The relationship within the community contributes to increasing the social wellbeing, an important component of the entrepreneur's perception of quality of life [32] and an essential factor for location decisions [33].

Based on the prior literature on tourism lifestyle entrepreneurship, we identified four key antecedent factors (predictors) of tourism lifestyle entrepreneurs' willingness to stay, namely community attachment, place attachment, entrepreneurial self-efficacy, and a community-centered strategy. Rather than hypothesizing the effect of each predictor on the willingness to stay, our study considers that these predictors can combine in multiple ways to predict the willingness to stay. Thus, by applying fsQCA, we analyze the possible combinations of the key antecedent factors (conditions) that are equifinal in leading to a willingness to stay (outcome).

\section{Research Methodology}

A mixed-method approach combines both quantitative and qualitative research (data collection and analysis) employed sequentially or simultaneously within a single study [34]. In this study, a mixed-method sequential approach was applied by combining quantitative and qualitative methods, where quantitative research was performed first and was followed by qualitative research.

The target population for this study included all Portuguese and Spanish TLEs. These TLEs were selected following the criteria suggested by Bosworth and Farrell [6] and Morrison [7], namely having a tourism-related business, sustaining the local traditions, environment, and heritage, independently running the business, and committing to expressing the local character of the destination. For both the qualitative and quantitative studies, the participants were from the Andalucía autonomous community (Spain) and from the center region of Portugal, and the confidentiality and anonymity of participants were ensured.

\subsection{Quantitative Research}

\subsubsection{Sample and Data Collection}

As previously presented, the target population for this study was Portuguese and Spanish TLEs. A non-probability sampling procedure was used. More specifically, convenience sampling was employed in selecting the TLEs during three tourism entrepreneurship meetings (i.e., Tourism-Up, Taste-Up, and Green-Up). To collect data, we applied an 
internet-based survey questionnaire. The questionnaire was initially developed through a review of the literature. Before conducting the main study, the questionnaire was first revised by three tourism academics to assess content validity. Then, a pilot test was conducted with five TLEs (two in nature tourism, one in hostels, one tour guide, and one cooking experiences restaurant) through face-to-face, semi-structured interviews. The internet-based survey questionnaire was sent to the 115 selected TLEs. A total of 115 complete responses were received.

In the final sample, most of the TLEs were from the center region of Portugal (74\%), mainly being from Lisbon (34\%), Coimbra (12\%), and Santarém (11\%), 62\% were born in the place where they currently had their tourism business, $66 \%$ were male, and $70 \%$ were between 40 and 60 years old. Most of the TLE stated that their firms had 10 or less employees (68\%), and the rest were small firms (less than 49 employees). An average of 7.26 years and a standard deviation of 5.47 years were obtained regarding the number of years in operation for their businesses.

\subsubsection{Measures}

The measurement items used to measure the latent constructs were drawn from the literature. The final measurement instrument is shown in Appendix A. The community attachment and community-centered strategy were measured by two and three items, respectively, which were adapted from Besser and Miller [35]. Place attachment was measured using two-item scales adapted from Lalli [36]. A three-item scale adapted from Zhao, Seibert, and Hills [37] was used to measure the entrepreneurial self-efficacy. We also adopted existing measures for our dependent variable (outcome) of the willingness to stay. More specifically, the willingness to stay was measured using four items adopted from Lalli [36]. Place attachment and the willingness to stay were measured using sevenpoint Likert-type scales anchored from one (strongly disagree) to seven (strongly agree). Entrepreneurial self-efficacy was measured by asking respondents to indicate the degree of confidence with a specific statement on a five-point Likert-type scale anchored from one (no confidence) to five (complete confidence). The community-centered strategy was assessed by asking respondents to evaluate the importance of specific strategies on a five-point Likert-type scale anchored from one (not important at all) to five (extremely important). The original scale range used by the authors was maintained to assure the adherence to their approach.

\subsubsection{Common Method Bias}

Because our study used data collected from a single informant, common method bias (CMB) could constitute a threat to the validity of our results [38]. In order to safeguard against common method bias, we followed some procedural remedies suggested by Podsakoff et al. [38]. More specifically, we created simple and concise items, protected the respondents' anonymity, placed the dependent variable after the independent variables in the survey, and pre-tested the questionnaire with the TLEs. In addition, we employed Harman's single-factor test. The results of the test showed that the non-rotated solution EFA analysis produced four factors with eigenvalues $>1$. Taken together, the four factors accounted for $72.4 \%$ of the variance in the data, with the first extracted factor accounting for $36.5 \%$ of the variance, which was below the threshold of $50 \%$ [38].

\subsubsection{Analytical Approach: Qualitative Comparative Analysis}

The empirical analysis in this study was performed by applying fuzzy set qualitative comparative analysis (fsQCA). This methodology has started to increase in popularity in tourism research (e.g., refs. $[39,40])$. FsQCA is a set theoretic analytical technique that allows for a fine-grained empirical investigation of causal complexity through the logic of set theory [41], equifinality to permit different, equally effective configurations of conditions that may lead to the same outcome, and asymmetric causality, which allows configurations that lead to an outcome different from the configurations, leading to the negation of it. The 
basic intuition underlying this technique is that the influence of the antecedent variables on a specific outcome depends how they are combined, rather than the premise that each antecedent variable has its own isolated net effect on the dependent variable as traditional correlation-based techniques.

In this study, we assumed that place attachment, community attachment, entrepreneurial self-efficacy, and a community-centered strategy could be combined in multiple ways, as represented by the different shaded areas in the Venn diagram of Figure 1, to achieve a high willingness to stay. As was stated before, fsQCA assumes causal asymmetry, which means that the explanation for a high willingness to stay is not necessarily the logical opposite of the explanation for low willingness to stay. Thus, this study also examined the combinations of the four antecedent conditions that lead to a low willingness to stay $(\sim \mathrm{wts})$.

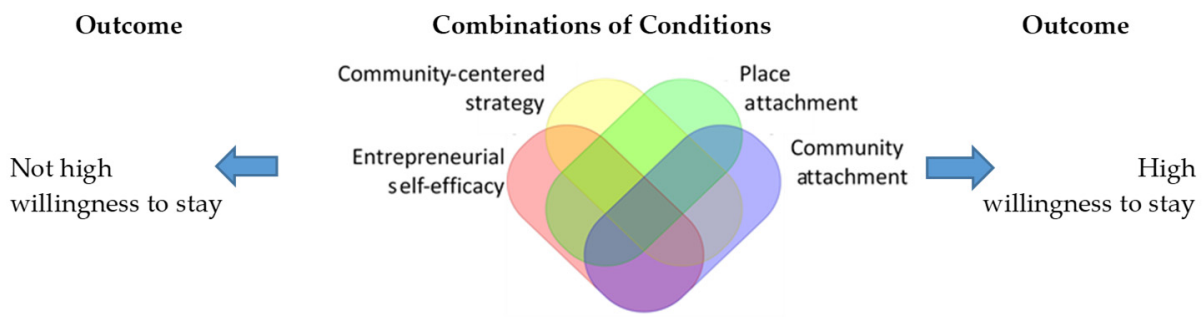

Figure 1. Venn diagram of the combination of conditions.

Calibration

FsQCA springs from the concept of set membership. Thus, analyzing data in fsQCA requires the transformation of the original variables into fuzzy sets (i.e., a set of membership scores ranging from zero (full exclusion from a set) to one (full inclusion)) [42]. This process, termed as calibration, requires specifying three different anchors: one to define full membership, another to define full non-membership, and a cross-over point [42]. In line with recent research [43] for calibrating each of the variables (both the conditions and the outcome) in the original data into a fuzzy set scale, we defined these anchors using three values: full membership was set at the original value that covered $95 \%$ of the data values, the cross-over point was set at the original value that covered $50 \%$ of the values, and full non-membership was set at the original value that covered $5 \%$ of the values.

\subsection{Qualitative Research}

With the analysis of the quantitative results, several additional questions arose, justifying the research team to return to the field to gather additional insights and deepen the results obtained. During the interview, the participants were asked to indicate other entrepreneurs who could participate in the study. As such, a non-probabilistic sampling method was used. The interviews asked questions based on the same constructs as in the previous study (relationship with the community, place, community-centered activities, and entrepreneurial self-efficacy). Life background was also asked about to understand how this influenced business initiatives and innovativeness.

An initial number of interviews was not set, as this would depend on the level of data saturation. At the end of 17 interviews, it was verified that the last 2 did not bring additional relevant information. However, to confirm saturation, three more interviews were carried out, and it was found that they did not provide any additional relevant information. In total, 20 interviews were conducted (7 B\&Bs, 6 in rural tourism, 5 tour guides, and 2 in gastronomic experiences). The average duration of each interview was $52 \mathrm{~min}$, and due to the pandemic context, they were mostly conducted through meeting platforms (e.g., Zoom and MSTeams). The data were processed using content analysis. 


\section{Results}

\subsection{Quantitative Research}

\subsubsection{Assessment of the Measurement Model}

Confirmatory factor analysis (CFA) using the maximum likelihood (ML) estimation method was conducted by means of IBM SPSS-AMOS 25.0 software to assess the reliability and validity of the latent variables. The goodness-of-fit statistics show that the proposed CFA model generally fit the data well $(\chi 2=102.86,(\mathrm{df}=68, p<0.01) ; \mathrm{CFI}=0.960$; TLI = 0.947; IFI $=0.961$, RMSEA $=0.067$, p-close $=0.145 ;$ standardized RMR $=0.063$ ). The CFA model complied with the commonly accepted thresholds for the evaluation of measurement models [44]. The CFI of 0.960, TLI of 0.947, and IFI of 0.961 met the recommended minimum threshold of 0.90 for an adequate fit [44]. The standardized RMR of 0.063 did not exceed the cut off of 0.10 , nor did the RMSEA of 0.067 exceed the cut off of 0.08 [44]. The standardized factor loadings, summarized in Appendix A, were generally above 0.7 and all significant at $p<0.001$. These results provide evidence of convergent validity [45].

To access measurement reliability and convergent validity, we analyzed Cronbach's coefficient alpha $(\alpha)$, the composite reliability $(\mathrm{CR})$, and the average variance extracted (AVE) for all constructs. As can be seen in Table 1, the $\alpha$ and CR values exceeded 0.7 for all constructs [45], and the AVE values were greater than 0.5 [45]. Moreover, for each latent variable, the AVE values were larger than the corresponding CR values. Taken together, these results support measurement reliability and convergent validity. To assess discriminant validity, we followed the procedure suggested by Fornell and Larcker [46]. We checked if the square root of the AVE of each construct-shown on the diagonal of Table 1-was higher than the correlations between all constructs [46]. The results show that this condition was satisfied for all constructs. Thus, discriminant validity was also supported.

Table 1. Correlation matrix (discriminant validity check).

\begin{tabular}{|c|c|c|c|c|c|c|c|c|}
\hline Latent Variables & $\alpha$ & CR & AVE & (1) & (2) & (3) & (4) & (5) \\
\hline (1) Community attachment & 0.74 & 0.75 & 0.61 & 0.78 & & & & \\
\hline (2) Place attachment & 0.73 & 0.81 & 0.68 & 0.21 & 0.82 & & & \\
\hline (3) Entrepreneurial self-efficacy & 0.77 & 0.78 & 0.56 & -0.03 & -0.09 & 0.74 & & \\
\hline (4) Community-centered strategy & 0.71 & 0.76 & 0.52 & 0.64 & 0.37 & 0.44 & 0.73 & \\
\hline (5) Willingness to stay & 0.92 & 0.94 & 0.80 & 0.71 & 0.36 & -0.04 & 0.44 & 0.89 \\
\hline
\end{tabular}

Note: The bolded diagonal values are the square root of the average variance extracted (AVE). CR = composite reliability; $\alpha=C$ ronbach's alpha; $\mathrm{AVE}=$ average variance extracted.

\subsubsection{Analysis of Necessary Conditions}

A causal condition, or a combination of causal conditions, is considered necessary if it is always present (or absent) when the outcome is present (or absent) [47]. According to the fsQCA literature. the analysis of necessary conditions should precede the analysis of sufficient conditions ([48], p. 204). Thus, we started the fsQCA analysis by determining if any of the four antecedent conditions were necessary for the outcomes of the willingness to stay and its negation.

Table 2 presents the results of the analysis of the necessity relative to the outcomes of both a high willingness to stay (wts) and the negation of a high willingness to stay ( wts). Conventionally, for a causal condition to be considered necessary, the consistency must be equal to or greater than 0.9 [42]. As can be seen in Table 2, none of the four conditions nor their negation were a necessary condition for the willingness to stay nor for its negation. A condition, or a combination of causal conditions, is "almost always necessary" if the consistency exceeds the threshold of 0.80 [49]. Table 2 shows that place attachment was an "almost always necessary" condition for the willingness to stay because its consistency score was 0.86 , exceeding the required threshold. 
Table 2. Overview of necessary conditions.

\begin{tabular}{lcccc}
\hline \multicolumn{1}{c}{ Condition } & \multicolumn{3}{c}{ Willingness to Stay (wts) } \\
\multicolumn{1}{c}{ wts } & \multicolumn{1}{c}{$\sim$ wts } \\
\hline Community attachment & Consistency & Coverage & Consistency & Coverage \\
C Community attachment & 0.66 & 0.71 & 0.49 & 0.48 \\
Place attachment & 0.52 & 0.53 & 0.71 & 0.65 \\
$\sim$ Place attachment & 0.88 & 0.82 & 0.44 & 0.37 \\
Entrepreneurial self-efficacy & 0.53 & 0.39 & 0.79 & 0.86 \\
$\sim$ Entrepreneurial self-efficacy & 0.60 & 0.63 & 0.55 & 0.56 \\
Community-centered strategy & 0.71 & 0.59 & 0.63 & 0.58 \\
$\sim$ Community-centered strategy & 0.48 & 0.73 & 0.50 & 0.46 \\
Note: $\sim$ represents the absence of a condition. Calculations performed with the fs/QCA 2.5 software [50].
\end{tabular}

\subsubsection{Analysis of Sufficient Conditions for Willingness to Stay}

A causal condition or combination of conditions is sufficient for an outcome if the outcome occurs when the condition (or combination of conditions) is present ([47], p. 184). The analysis of sufficiency followed three sequential steps [42,51]. First, the truth table, listing all logical combinations of the four conditions $(24=16)$ and the respective number of empirical instances, was constructed. Secondly, the truth table was reduced to meaningful configurations based on two criteria: frequency, which described the number of empirical instances for each possible combination, and consistency, which referred to "the degree to which cases correspond to the set theoretic relationships expressed in a solution" ([51], p. 402). We set the minimum frequency threshold at five, which ensured that only configurations that had at least five best-fit cases were kept (cf. [47], p. 107). With respect to consistency, the lowest acceptable consistency score was set at 0.8 [42]. In addition, we also inspected the proportional reduction in inconsistency (PRI) and eliminated any configuration that had a PRI lower than or equal to 0.7 to avoid simultaneous subset relations of attribute combinations in both the outcome and the negation $[48,51]$. Finally, using Boolean minimization and the Quine-McCluskey algorithm [42], the truth table was reduced to simplified configurations.

The Quine-McCluskey algorithm incorporates an analysis of counterfactual cases known as counterfactual analysis, which differentiates between easy and difficult counterfactuals (see [51], p. 403). Based on the differences in these two types of counterfactuals, the truth table algorithm produced three solutions (complex, intermediate, and parsimonious) and allowed us to distinguish antecedent conditions as "core" or "peripheral" [51]. Core conditions appeared in both the intermediate and parsimonious solutions, while peripheral conditions only appeared in the intermediate solution. For both outcomes (high and not high willingness to stay), we reported the fuzzy-set intermediate solution and distinguished between the "core" and "peripheral" conditions [51]. Table 3 provides the fuzzy set intermediate solution for high and not high (low) willingness to stay.

The goodness of fit of the solution could be evaluated using two measures: consistency and coverage. We used the formulas defined by Ragin [42] to calculate these measures as presented in Corne and Peypoch ([39], p. 4). The consistency value of each configuration describes the extent to which the empirical cases that share the configuration agree in displaying the outcome [51]. The consistency and coverage were calculated using the formulas proposed by Ragin (2008) and presented by Corne and Peypoch [39], which were the formulas used for the results presented in Table 3, showing that the intermediate solution for high willingness to stay (wts) comprised three configurations. The consistency scores for all configurations as well as the consistency score of the overall solution exceeded the threshold of 0.8 [42]. Thus, all configurations could be considered sufficient for wts. Coverage assesses the proportion of cases that follow a particular path and captures the empirical importance of a configuration [42]. Unique coverage refers to the proportion of cases explained exclusively by one configuration. Table 3 shows that the unique coverage was higher than zero for all configurations. Thus, all configurations were empirically rele- 
vant. The overall solution coverage refers to the joint importance of all configurations [42]. Table 3 shows that the three configurations explained $76 \%$ of the wts.

Table 3. Configurations for high and low willingness to stay.

\begin{tabular}{|c|c|c|c|c|c|}
\hline \multirow[b]{2}{*}{ Configuration } & \multicolumn{3}{|c|}{$\begin{array}{l}\text { High Willingness to Stay } \\
\text { (wts) }\end{array}$} & \multicolumn{2}{|c|}{$\begin{array}{l}\text { Low Willingness to } \\
\text { Stay ( wts) }\end{array}$} \\
\hline & $\mathrm{C} 1$ & $\mathrm{C} 2$ & $\mathrm{C} 3$ & $\mathrm{C} 4$ & C5 \\
\hline Community attachment & & $\otimes$ & $\bullet$ & & $\otimes$ \\
\hline Place attachment & O & O & O & $\otimes$ & $\otimes$ \\
\hline Entrepreneurial self-efficacy & & $\bullet$ & $\otimes$ & & - \\
\hline Community-centered strategy & $\bullet$ & & & $\otimes$ & \\
\hline Consistency & 0.86 & 0.85 & 0.93 & 0.91 & 0.89 \\
\hline Raw coverage & 0.64 & 0.31 & 0.40 & 0.61 & 0.33 \\
\hline Unique coverage & 0.20 & 0.05 & 0.06 & 0.33 & 0.05 \\
\hline Overall solution consistency & \multicolumn{3}{|c|}{0.84} & & 0.89 \\
\hline Overall solution coverage & \multicolumn{3}{|c|}{0.76} & & 0.68 \\
\hline
\end{tabular}

Notes: Large circles indicate core conditions and small circles peripheral conditions. Black circles ("O) indicate the "presence" of a condition, and circles with a cross-out (" $\otimes$ ") indicate its "negation". Blank spaces in the configurations indicate "do not care".

The examination of the intermediate solution for wts shows that place attachment was present in all configurations. In all configurations, place attachment was the single core condition. The first configuration indicated that a high level of place attachment in combination with a high community-centered strategy, regardless of the level of community attachment and entrepreneurial self-efficacy, led to a high willingness to stay. The second shows that a high level of place attachment in combination with high entrepreneurial self-efficacy and with low community attachment also led to a wts. The third indicates that a high level of place attachment combined with a high level of community attachment and with low entrepreneurial self-efficacy also led to a wts, regardless of the level communitycentered strategy.

As stated before, fsQCA accounts for causal asymmetry, which means that configurations that predict a high willingness to stay are not necessarily the mirror opposites of configurations that predict a low willingness to stay [51]. Thus, we also analyzed the configurations that led to a low willingness to stay ( $\sim \mathrm{wts})$. The frequency, consistency, and PRI thresholds used to perform the sufficiency analysis for the outcome of $\sim$ wts were the same as those used for a high willingness to stay. Table 3 presents the fuzzy set intermediate solution for $\sim$ wts (configurations C4 and C5). The results show that two configurations led to $\sim w t s$, and both exceeded the consistency threshold of 0.8 [42]. These configurations explained $68 \%$ of $\sim$ wts. Configuration 4 shows that the combination of a low communitycentered strategy (core condition) with low entrepreneurial self-efficacy (core condition) led to $\sim$ wts. Configuration 5 shows that high entrepreneurial self-efficacy combined with low place attachment and low community attachment also led to $\sim$ wts. In this configuration, low place attachment and low community attachment were core conditions.

\subsection{Qualitative Research}

The set of TLEs interviewed was distributed as follows: five were born and had always lived in the place where they operated their businesses, eight came from outside, and the remaining seven were born in the place where they operated their businesses but had lived part of their lives elsewhere, having returned to their origins to create their businesses.

The first group was unanimous in stating that the will to stay in the place was independent of the evolution of the business. For them, it was not part of their life plan to move to other places, even if the current business did not go as expected. In the words of the interviewees: 
"This is where our roots, friends and family are. This is where we like to be, close to our own. Business comes and goes."

"With this, it is the third business we have created here. We are very satisfied with the current business (rural tourism) even despite the effects of the pandemic"

This group included two of those who were born there but went to live outside, all those who had always stayed there, and only one who came from outside. The profile of the responses in terms of a strong connection to the community and place and low entrepreneurial self-efficacy resembled configuration 3 of the quantitative study. Furthermore, the businesses run by these entrepreneurs were very traditional, with a strong focus on the host-visitor relationship quality and less on innovative products or services.

The second group revealed that although they were attracted to the local culture, natural environment, and lifestyle, they had reduced connections to the community. The group was composed mostly of people who were born in the place where they developed their businesses but had spent a significant part of their life away and had lost the relationship with the local community. The question of financial objectives was less relevant because they already had a way of sustaining themselves. Therefore, whether by retirement or by disenchantment with life elsewhere, where they have already accumulated capital, they had come to stay, even if the business did not run in the best way:

"We came here and created our dining experience business six months ago ( ... ) we are still seeing if it is the best option."

On the other hand, due to the strong attachment to the place, this group proved to be very committed to local traditions, actively promoting innovative cultural initiatives such as events, meetings, fairs and museums:

"We think that this locality has been decharacterizing and losing its identity (... ). We created the museum so that the memory and traditions of this place are not lost. We provide several pieces of the collection of the museum."

Thus, this group was close to configuration 1 of the quantitative study, where the drivers of willingness to stay were place attachment and community-centered strategies.

The third group was mostly composed of people who came from outside, having been attracted to live there by the lifestyle and the natural and cultural context of the region. In the words of one interviewee:

"We always had the passion for this place, we came several times as tourists until, as a family, we decided to change our lives and bought a house. (... ) We seek to have a competitive and profitable business."

For this group, the fact that they did not have roots justified the reduced community attachment and pushed them to have a sharp business vision. The business orientation resulted not only from the need to pay the bills at the end of the day but also from professional experiences when living elsewhere. Despite having a strong place attachment, they would be willing to look for other locations to set up a business or get a job if the business did not match up to their expectations. As one of the interviewees stated:

"We have two children to support and several expenses to pay at the end of each month. (...) We have been prospecting in other locations where we can conduct tours if the demand declines." 
Thus, this group was close to configuration 2 as revealed by the quantitative study, in which there was a weak connection with the local community. For these entrepreneurs, staying in the location depended on the passion for the place when combined with the perceived success in the business. They presented innovative experiences to the tourists, eventually with a lower relation to the place's culture and identity (e.g., adventure tours, sunset events, or bee-related products or experiences).

\section{Discussion}

Place attachment is a core condition common to all paths related to a strong willingness to stay. This result aligns with the assumption that the place plays an essential role in location decisions (cf. [52]). However, on its own, this factor is not sufficient to explain the willingness to stay and must be associated with other factors, with $76 \%$ of the explained variance found to fall under three conditions. In configuration 1, the willingness to stay was associated with a community-centered strategy, revealing the active role of the entrepreneur in the community where he or she operated. In their study, Holland and Martin [53] found that entrepreneurs who come from outside are usually highly educated and have chosen a particular location for the lifestyle. The authors also mentioned that these entrepreneurs left their careers for a business in tourism perceived as merely instrumental to achieve the desired lifestyle. Previous research also recognizes the pursuit of community-centered strategies as an important aspect for the acquisition of local knowledge through activities involving the local community, which work as a magnet to attract knowledge [24]. This finding contributes to the literature by identifying a type of entrepreneur who seeks to play an active role in the community, despite lacking strong place attachment. As Shaw and Williams [12] pointed out, tourism entrepreneurs tend to be integrated in the local community, influencing it and being influenced by it.

In configuration 2, the willingness to stay is the result of place attachment in conjunction with entrepreneurial self-efficacy and a reduced level of community attachment. In this case, the results suggest that the entrepreneur is business-oriented, a situation in which satisfaction with the business results is more important than the connection to the community, allowing perceiving that there is a focus on selling the place. As $\mathrm{Su}$, Zhang, and Cai [54] mentioned, tourism is a metaphor for the chosen lifestyle and a sense of belonging to a place. These results not only confirm a previously identified entrepreneur pattern of business-oriented [15] in which the place is for making profit [54] but also extends existing knowledge about self-efficacy as motivation to stay in a specific location.

Configuration 3 shows a strong relationship with the place and the community, even when the business results are not satisfactory. This is a purely lifestyle-oriented configuration in which satisfaction with the business is essentially instrumental. Configuration 5 shows that the reduced willingness to stay is associated with a low relationship with the place and the community but with strong entrepreneurial self-efficacy. Thus, perceived business success is less dependent on the location and could be located elsewhere. As revealed by Hallak et al. [55], self-efficacy is an important predictor of business performance. Returning to configuration 3, this denial allows for the recognition that the importance of the place and the degree of integration into the local community play an essential role in location decisions in small tourism businesses [56]. A low place attachment combined with a low community-centered strategy is also associated with a reduced willingness to stay (configuration C4).

Our findings have important implications by identifying three different configurations or paths, revealing that the TLE location decision is not the result of rational economic factors, providing important insights for decision making and the ongoing discussion concerning the different TLE groups or segments.

The combination of the two studies allows for identification and deeper knowledge of the three configurations. This shows that although place attachment is a common factor in the entrepreneur's willingness to stay in a certain destination, it is not a sufficient condition by itself. It is necessary to combine other factors, which points to three possible 
scenarios that are related to distinct classes of entrepreneurs, as depicted in Figure 2. Two are linked to the relationship with the community, and the third does not contemplate this relationship.

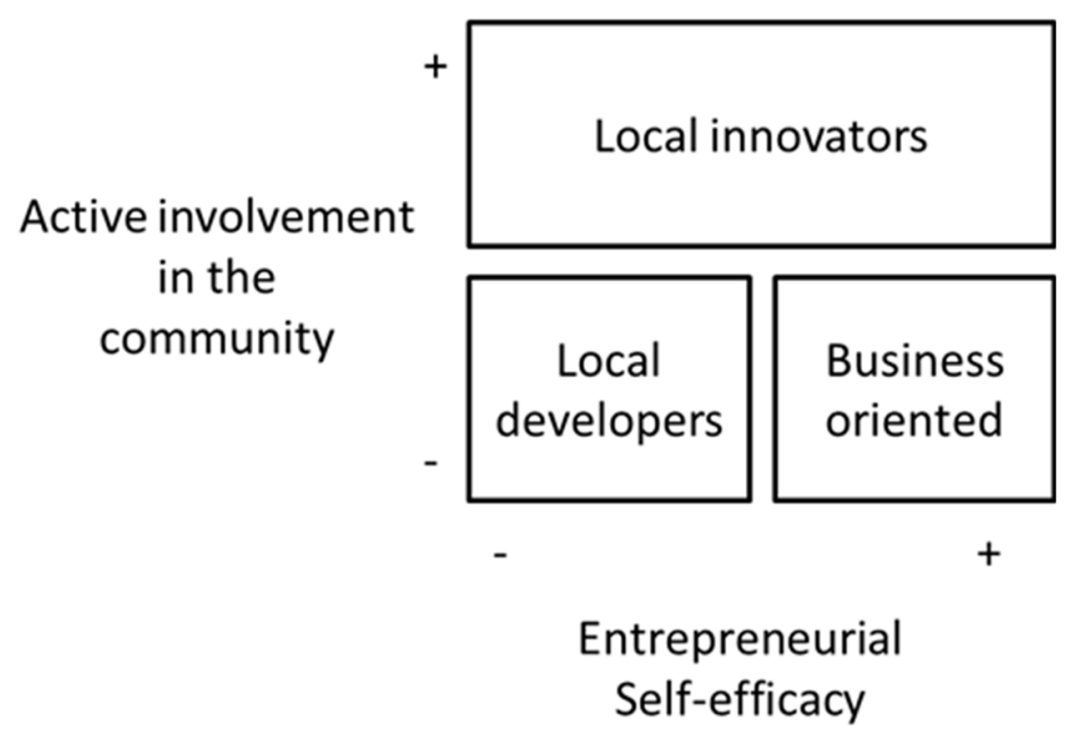

Figure 2. Classes of lifestyle entrepreneurs.

The first class is constituted by the local developers and integrates mainly native entrepreneurs who have been living in the same place where they developed their businesses. They are well integrated in the local community and show strong place attachment. Despite their strong local identity, they are not exactly innovative, as they run traditional businesses focused on the host-visitor relation, and their businesses are considered instrumental to follow their desired lifestyles. Their willingness to stay is high, even in situations of weak business performance.

We named the second class local innovators, composed of entrepreneurs that have a strong link to the community and normally run more innovative businesses when compared with the previous group. This class aligns with the categorization of "innovative" presented by Dias et al. [57]. Although most of them were native to the place, they spent a significant part of their lives in other locations. As a result, they brought ideas that were new to the place based on their life experiences and personal contacts, which were very useful as a sales channel. For them, although entrepreneurial self-efficacy was important, it was not determinant to stay at the destination. However, they play a key role in the destination dynamism by pursuing actively community-centered strategies.

The third class is constituted by the business-oriented lifestyle entrepreneurs. Based on the results, they are not native to the place, but they are attracted to it by the lifestyle, culture, or natural environment. However, the willingness to stay depends on the results of the business, and they will move to other locations if the performance perception is not satisfactory. Although they like the place, they are also there for a business reason.

\section{Conclusions}

\subsection{Theoretical Contributions}

The contributions of this study to tourism entrepreneurship theory are fourfold. First, it extends existing knowledge on the attraction and retention of TLEs by identifying classes of entrepreneurs who value distinct combinations of factors regarding where they develop their businesses. Previous research recognized the existence of a set of factors contributing to the willingness to stay [14]; however, it did not establish such differentiation regarding the preferences and interests of distinct classes of entrepreneurs. Second, it recognizes that place attachment is a core factor common to all classes of TLEs identified regarding the willingness to stay in a place, which allows not only a clear identification of this factor 
as a key element in the development of the territory's development strategies but also realizing that community attachment is not always a key factor, as was previously assumed. Third, this study advances the consolidation of the attraction and retention factors of TLEs which, as mentioned, play an essential role in the innovation and competitiveness of the tourist destination. In this context, the ability to constitute a pool of these entrepreneurs is something essential, although explored very little, in academic research, as recognized by Dias and Silva [58]. Fourth, the novelty of this study also results from considering the willingness to stay as a dependent variable, while establishing various configurations of antecedents, which provides important insights into the theoretical knowledge regarding entrepreneurial ecosystems in tourism.

\subsection{Practical Implications}

The results of this study also provide important insights for the development of the competitiveness and innovation of tourism destinations. The results reveal the essential role that place attachment plays in attracting and retaining TLEs. Thus, the strategies and actions leading to the construction and consolidation of local culture and identity, aside from being an essential element in attracting tourists, are also of the utmost importance in retaining entrepreneurs.

Through the identification of distinct classes of TLEs, it is also noted that place attachment is not the only condition for retention of these entrepreneurs. Rather, it should be combined with other individual factors such as community attachment or organizational factors such as community-centered strategies or entrepreneur self-efficacy. In this scenario, the development of policies to foster local entrepreneurship based on subsidies that are determined by the achievement of financial objectives should be rethought. Only one of the classes of entrepreneurs (business-oriented) considered the achievement of business results as important for staying in the location. However, the other entrepreneurs are also important in terms of innovation, job creation, and wealth creation. Evaluating the access to public (governmental or from EU) subsidies solely based on financial results is somewhat reductive.

The fact that three classes of TLEs were identified reveals that there are differences both in the background of each entrepreneur and in business performance and that there should not be "one-size-fits-all" policies. In some cases, it is important to guarantee support for events, festivities, and other community-centered strategies, while in others, it is essential to support the conversion of deep local knowledge, which results from strong community attachment, into innovative and differentiated services and experiences.

\subsection{Limitations and Future Research}

This study also presents some limitations and points out avenues for future research. Naturally, the convenience sample could be enlarged, although we acknowledge the difficulty in obtaining responses from these types of entrepreneurs. In high season, they are not available to answer due to a lack of time, and in low season, it is also not easy because these are moments dedicated to leisure and family. In this study, we used the willingness to stay as a dependent variable. It will also be interesting to study the impact of the same variables in the perception of quality of life, since it is one of the main objectives of these entrepreneurs. The dichotomy between rural and urban destinations could also be an interesting variable to include in the model, especially as a moderating factor.

This study also opens doors to understanding the evolution of entrepreneurs in life course changes. Indeed, many of the entrepreneurs are from abroad or are locals who have been away for part of their lives. A longitudinal follow-up will be worthwhile for understanding changes in the way the factors used influence the willingness to stay and the quality of life. Finally, it might be interesting to complement the variable for business performance used in the study (entrepreneurial self-efficacy) with other business indicators like EBITDA, profitability of assets, and other financial rations. 
Author Contributions: Conceptualization, Á.D. and G.M.S.; methodology, Á.D. and G.M.S.; validation, G.M.S.; formal analysis, Á.D. and G.M.S.; investigation, Á.D.; data curation, Á.D.; writingoriginal draft preparation, Á.D. and G.M.S. All authors have read and agreed to the published version of the manuscript.

Funding: This work was supported by the Fundação para a Ciencia e Tecnologia (FCT) (grant number UIDB/04521/2020) and ADVANCE/CSG.

Institutional Review Board Statement: Ethical review and approval were waived for this study, since that the in-depth interviews written informed consent was obtained before each session. In the survey, a link to the online survey platform was sent by social media and partners social media, and at no times contact was established between researchers and participants. Moreover, the interview script and the questionnaire personal did not include any information and recording histories. As such, all data accessible to the researchers were stripped of respondents' names, addresses, or birth dates and cannot be linked back.

Informed Consent Statement: Informed consent was obtained from all subjects involved in the study.

Data Availability Statement: Data will be provided upon reasonable request.

Conflicts of Interest: The authors declare no conflict of interest.

\section{Appendix A}

Table A1. Construct indicators: Measurement scales, descriptive statistics, standardized factor loadings, and $t$-values.

\begin{tabular}{|c|c|c|c|c|}
\hline Constructs and Items & Mean & SD & SFL & $t$-Value \\
\hline \multicolumn{5}{|l|}{ Community attachment $(1=$ none; $7=$ strong $)$} \\
\hline Proportion of friends who live at or near this location & 6.26 & 1.16 & 0.80 & - a \\
\hline Proportion of family members who live in or near this place & 6.30 & 1.09 & 0.85 & 8.02 \\
\hline \multicolumn{5}{|l|}{ Community-centered strategy $(1=$ not important at all; $7=$ extremely important $)$} \\
\hline I seek to strengthen and improve the local community & 6.03 & 1.30 & 0.91 & $\_\mathrm{a}$ \\
\hline I seek to improve my image with the local community & 5.75 & 1.43 & 0.60 & 6.25 \\
\hline I am addressing clients that are not served by other local companies & 5.32 & 1.78 & 0.63 & 6.65 \\
\hline \multicolumn{5}{|l|}{ Entrepreneurial self-efficacy ( $1=$ no confidence; $5=$ complete confidence) } \\
\hline I successfully identify new opportunities & 4.37 & 0.67 & 0.57 & $\_\mathrm{a}$ \\
\hline I create new products & 4.30 & 0.77 & 0.81 & 5.61 \\
\hline I think creatively & 4.52 & 0.65 & 0.82 & 5.60 \\
\hline \multicolumn{5}{|l|}{ Place Attachment ( 1 = strongly disagree; 7 = strongly agree $)$} \\
\hline I really feel at home in this place & 3.91 & 1.14 & 0.89 & _a \\
\hline This place is like a part of myself & 3.35 & 1.51 & 0.65 & 6.69 \\
\hline \multicolumn{5}{|l|}{ Willingness to stay ( 1 = strongly disagree; 7 = strongly agree $)$} \\
\hline I would like to stay indefinitely in this place & 5.39 & 1.64 & 0.761 & _a \\
\hline I wish to follow the future development of this place & 6.19 & 1.25 & 0.940 & 11.32 \\
\hline This site plays an important role in my future plans & 6.02 & 1.40 & 0.973 & 11.77 \\
\hline My personal future is connected to this place & 5.76 & 1.56 & 0.877 & 10.36 \\
\hline
\end{tabular}

Notes: _a = a parameter that was fixed at 1.0; SFL = standardized factor loadings; SD = standard deviation.

\section{References}

1. Richards, G. Creativity and tourism: The state of the art. Ann. Tour. Res. 2011, 38, 1225-1253. [CrossRef]

2. Yachin, J.M. The entrepreneur-opportunity nexus: Discovering the forces that promote product innovations in rural micro-tourism firms. Scand. J. Hosp. Tour. 2019, 19, 47-65. [CrossRef]

3. Shrivastava, P.; Kennelly, J.J. Sustainability and place-based enterprise. Organ. Environ. 2013, 26, 83-101. [CrossRef]

4. Thomas, R.; Shaw, G.; Page, S.J. Understanding small firms in tourism: A perspective on research trends and challenges. Tour. Manag. 2011, 32, 963-976. [CrossRef]

5. Sun, X.; Xu, H. Role Shifting Between Entrepreneur and Tourist: A Case Study on Dali and Lijiang, China. J. Travel Tour. Mark. 2019, 37, 547-561. [CrossRef]

6. Bosworth, G.; Farrell, H. Tourism entrepreneurs in Northumberland. Ann. Tour. Res. 2011, 38, 1474-1494. [CrossRef]

7. Morrison, A. A contextualisation of entrepreneurship. Int. J. Entrep. Behav. Res. 2006, 12, 192-209. [CrossRef]

8. Dias, Á.L.; Silva, R.; Patuleia, M.; Estêvão, J.; González-Rodríguez, M.R. Selecting lifestyle entrepreneurship recovery strategies: A response to the COVID-19 pandemic. Tour. Hosp. Res. 2021, 1-7. [CrossRef] 
9. Bredvold, R.; Skålén, P. Lifestyle entrepreneurs and their identity construction: A study of the tourism industry. Tour. Manag. 2016, 56, 96-105. [CrossRef]

10. Zhang, C.; Xiao, H.; Gursoy, D.; Rao, Y. Tacit knowledge spillover and sustainability in destination development. J. Sustain. Tour. 2015, 23, 1029-1048. [CrossRef]

11. Dias, Á.; Silva, G.M.; Patuleia, M.; González-Rodríguez, M.R. Transforming local knowledge into lifestyle entrepreneur's innovativeness: Exploring the linear and quadratic relationships. Curr. Issues Tour. 2020, 24, 3222-3238. [CrossRef]

12. Shaw, G.; Williams, A.M. Entrepreneurship, small business culture and tourism development. In Economic Geography of Tourism; Debbage, K., Ioannides, D., Eds.; Routledge: London, UK, 1998; pp. 235-255.

13. Lafuente, E.; Vaillant, Y.; Serarols, C. Location decisions of knowledge-based entrepreneurs: Why some Catalan KISAs choose to be rural? Technovation 2010, 30, 590-600. [CrossRef]

14. Dias, Á.; González-Rodríguez, M.R.; Patuleia, M. Retaining tourism lifestyle entrepreneurs for destination competitiveness. Int. J. Tour. Res. 2021, 23, 701-712. [CrossRef]

15. Wang, S.; Hung, K.; Huang, W.J. Motivations for entrepreneurship in the tourism and hospitality sector: A social cognitive theory perspective. Int. J. Hosp. Manag. 2019, 78, 78-88. [CrossRef]

16. Pappas, N.; Papatheodorou, A. Tourism and the refugee crisis in Greece: Perceptions and decision-making of accommodation providers. Tour. Manag. 2017, 63, 31-41. [CrossRef]

17. Lundberg, C.; Fredman, P. Success factors and constraints among nature-based tourism entrepreneurs. Curr. Issues Tour. 2012, 15, 649-671. [CrossRef]

18. Ioannides, D.; Petersen, T. Tourism 'non-entrepreneurship'in peripheral destinations: A case study of small and medium tourism enterprises on Bornholm, Denmark. Tour. Geogr. 2003, 5, 408-435. [CrossRef]

19. Cooper, C. Managing tourism knowledge. Tour. Recreat. Res. 2015, 40, 107-119. [CrossRef]

20. Fu, H.; Okumus, F.; Wu, K.; Köseoglu, M.A. The entrepreneurship research in hospitality and tourism. Int. J. Hosp. Manag. 2019, 78, 1-12. [CrossRef]

21. Ateljevic, I.; Doorne, S. Staying within the fence': Lifestyle entrepreneurship in tourism. J. Sustain. Tour. 2000, 8, 378-392. [CrossRef]

22. Wang, C.; Li, G.; Xu, H. Impact of lifestyle-oriented motivation on small tourism enterprises' social responsibility and performance. J. Travel Res. 2019, 58, 1146-1160. [CrossRef]

23. Chen, C.C.; Greene, P.G.; Crick, A. Does entrepreneurial self-efficacy distinguish entrepreneurs from managers? J. Bus. Ventur. 1998, 13, 295-316. [CrossRef]

24. Dias, Á.; Silva, G.M.; Patuleia, M.; González-Rodríguez, M.R. Developing sustainable business models: Local knowledge acquisition and tourism lifestyle entrepreneurship. J. Sustain. Tour. 2020, 1-20. [CrossRef]

25. Valtonen, A. Small tourism firms as agents of critical knowledge. Tour. Stud. 2009, 9, 127-143. [CrossRef]

26. Czernek, K. Tourism features as determinants of knowledge transfer in the process of tourist cooperation. Curr. Issues Tour. 2017, 20, 204-220. [CrossRef]

27. Koh, K.Y.; Hatten, T.S. The tourism entrepreneur: The overlooked player in tourism development studies. Int. J. Hosp. Tour. Adm. 2002, 3, 21-48. [CrossRef]

28. Arias, R.A.C.; Cruz, A.D. Rethinking artisan entrepreneurship in a small island. Int. J. Entrep. Behav. Res. 2019, $25,633-651$. [CrossRef]

29. Marchant, B.; Mottiar, Z. Understanding lifestyle entrepreneurs and digging beneath the issue of profits:Profiling surf tourism lifestyle entrepreneurs in Ireland. Tour. Plan. Dev. 2011, 8, 171-183. [CrossRef]

30. Eikhof, D.R.; Haunschild, A. Lifestyle meets market: Bohemian entrepreneurs in creative industries. Creat. Innov. Manag. 2006, 15, 234-241. [CrossRef]

31. Schilar, H.; Keskitalo, E. Tourism activity as an expression of place attachment-place perceptions among tourism actors in the Jukkasjärvi area of northern Sweden. Scand. J. Hosp. Tour. 2018, 18, 42-59. [CrossRef]

32. Peters, M.; Kallmuenzer, A.; Buhalis, D. Hospitality entrepreneurs managing quality of life and business growth. Curr. Issues Tour. 2018, 22, 2014-2033. [CrossRef]

33. Benson, M.; O'Reilly, K. Migration and the search for a better way of life: A critical exploration of lifestyle migration. Sociol. Rev. 2009, 57, 608-625. [CrossRef]

34. Creswell, J.W. Research design: Qualitative, Quantitative, and Mixed Methods Approaches; Sage publications: Thousand Oaks, CA, USA, 2013.

35. Besser, T.L.; Miller, N. Is the good corporation dead? The community social responsibility of small business operators. J. Socio-Econ. 2001, 30, 221-241. [CrossRef]

36. Lalli, M. Urban-related identity: Theory, measurement, and empirical findings. J. Environ. Psychol. 1992, 12, 285-303. [CrossRef]

37. Zhao, H.; Seibert, S.E.; Hills, G.E. The mediating role of self-efficacy in the development of entrepreneurial intentions. J. Appl. Psychol. 2005, 90, 1265. [CrossRef] [PubMed]

38. Podsakoff, P.M.; MacKenzie, S.B.; Lee, J.-Y.; Podsakoff, N. Common method biases in behavioral research: A critical review of the literature and recommended remedies. J. Appl. Psychol. 2003, 88, 879-903. [CrossRef] [PubMed]

39. Corne, A.; Peypoch, N. On the determinants of tourism performance. Ann. Tour. Res. 2020, 85, 103057. [CrossRef] 
40. Ham, J.; Koo, C.; Chung, N. Configurational patterns of competitive advantage factors for smart tourism: An equifinality perspective. Curr. Issues Tour. 2020, 23, 1066-1072. [CrossRef]

41. Misangyi, V.F.; Greckhamer, T.; Furnari, S.; Fiss, P.C.; Crilly, D.; Aguilera, R. Embracing causal complexity: The emergence of a neo-configurational perspective. J. Manag. 2017, 43, 255-282. [CrossRef]

42. Ragin, C.C. Redesigning Social Inquiry: Fuzzy Sets and Beyond; University of Chicago Press: Chicago, IL, USA, 2008.

43. Woodside, A.G. Moving beyond multiple regression analysis to algorithms: Calling for adoption of a paradigm shift from symmetric to asymmetric thinking in data analysis and crafting theory. J. Bus. Res. 2013, 66, 463-472. [CrossRef]

44. Kline, R.B. Principles and Practice of Structural Equation Modelling, 4th ed.; Guilford Press: New York, NY, USA, 2015.

45. Bagozzi, R.P.; Yi, Y. Specification, evaluation, and interpretation of structural equation models. J. Acad. Mark. Sci. 2012, 40, 8-34. [CrossRef]

46. Fornell, C.; Larcker, D. Evaluating structural equation models with unobservable variables and measurement error. J. Mark. Res. 1981, 18, 29-50. [CrossRef]

47. Rihoux, B.; Ragin, C.C. Configurational Comparative Methods: Qualitative Comparative Analysis (QCA) and Related Techniques; Sage: Los Angeles, CA, USA, 2009.

48. Schneider, C.Q.; Wagemann, C. Set-Theoretic Methods for the Social Sciences: A Guide to Qualitative Comparative Analysis; Cambridge University Press: Cambridge, UK, 2012.

49. Ragin, C.C. Fuzzy-Set Social Science; University of Chicago Press: Chicago, IL, USA, 2000.

50. Ragin, C.; Davey, S. fs/QCA [Computer Programme], version 2.5; University of California: Irvine, CA, USA, 2014.

51. Fiss, P.C. Building better causal theories: A fuzzy set approach to typologies in organization research. Acad. Manag. J. 2011, 54, 393-420. [CrossRef]

52. Allardyce, S. A continuum Approach to Lifestyle Entrepreneurship; Robert Gordon University: Aberdeen, UK, 2015.

53. Holland, C.; Martin, E. Lifestyle migration and work choices. Hosp. Soc. 2015, 5, 23-42. [CrossRef]

54. Su, X.; Zhang, H.; Cai, X. Lifestyle, profit, and the selling of home to tourists in Lijiang, China. Tour. Geogr. 2020, 23, 1001-1020. [CrossRef]

55. Hallak, R.; Assaker, G.; Lee, C. Tourism entrepreneurship performance: The effects of place identity, self-efficacy, and gender. J. Travel Res. 2015, 54, 36-51. [CrossRef]

56. Mottiar, Z. Lifestyle entrepreneurs and spheres of inter-firm relations: The case of Westport, Co Mayo, Ireland. Entrep. Innov. 2007, 8, 67-74. [CrossRef]

57. Dias, Á.; González-Rodríguez, M.R.; Patuleia, M. Creative tourism destination competitiveness: An integrative model and agenda for future research. Creat. Ind. J. 2021, 1-24. [CrossRef]

58. Dias, Á.; Silva, G.M. Lifestyle Entrepreneurship and Innovation in Rural Areas: The Case of Tourism Entrepreneurs. J. Small Bus. Strategy 2021, 31, 40-49. [CrossRef] 